\title{
Chronic Glaucoma in Northern Ghana-A Retrospective Study of 397 Patients
}

\author{
J. D. VERREY, ${ }^{1}$ A. FOSTER, ${ }^{2}$ R. WORMALD ${ }^{2}$ and C. AKUAMOA ${ }^{1}$ \\ Ghana and London
}

\begin{abstract}
Summary
A retrospective study of $\mathbf{3 9 7}$ patients with chronic glaucoma in North-East Ghana seen in $1986 / 87$ showed $71 \%$ of the patients to be male and $26 \%$ to be aged under 40 years. Fifty two per cent of eyes were already blind (V/A less than 3/60) at presentation. Blindness was associated with younger age at presentation, and greater distance of residence from the hospital.

Only $19 \%$ of patients undergoing treatment were attending for follow-up at six months. Of those patients treated medically who returned for follow-up at six months only $17 \%$ had an intraocular pressure less than $22 \mathrm{mmHg}$. While of the patients treated surgically $84 \%$ of those seen at six months had an IOP below 22 mmHg.
\end{abstract}

In parts of West Africa, chronic glaucoma is responsible for over $20 \%$ of blindness (binocular visual acuity less than 3/60). ${ }^{1}$ Glaucoma occurs at an earlier age, is more aggressive and is said to respond less well to treatment in people of African origin. ${ }^{2,3}$ In an effort better to understand some of the factors which lead to blindness from glaucoma in West Africa a retrospective study of 397 patients with chronic glaucoma was undertaken in Northern Ghana at Bawku hospital.

\section{Methods}

A description of the hospital and terrain is given elsewhere. ${ }^{4}$ Records of all patients attending Bawku Hospital between January 1 1986 and July 301987 (19 months) were examined in order to identify patients presenting with chronic glaucoma. Those with acute glaucoma or obvious secondary glaucoma (eg trauma, swollen lens) were excluded. Because gonioscopy was not routinely performed it was not possible to distinguish between patients with chronic open angle and those with chronic angle closure due to peripheral anterior synechiae.

The diagnostic criteria used for inclusion in the study were an intraocular pressure greater than $28 \mathrm{mmHg}$ (Schiotz), in the presence of documented pathological cupping of the optic disc. Information on visual field examination was not usually available. From the patient's hospital record, age (sometimes estimated), sex, residence, visual acuity, intraocular pressure, optic disc appearance, treatment, duration of follow-up and outcome were recorded.

Associations between blindness at presentation, age, sex and distance of residence from the hospital were analysed using multivariate log linear regression on an IBM compatible

From: 'Bawku Hospital, Bawku, Ghana. ${ }^{2} \mathrm{ICEH}$, Institute of Ophthalmology, 27 Cayton Street, London EC1V 9EJ.

Correspondence to: Dr. A. Foster, FRCS, ICEH, Institute of Ophthalmology, 27 Cayton Street, London EC1V 9EJ. 


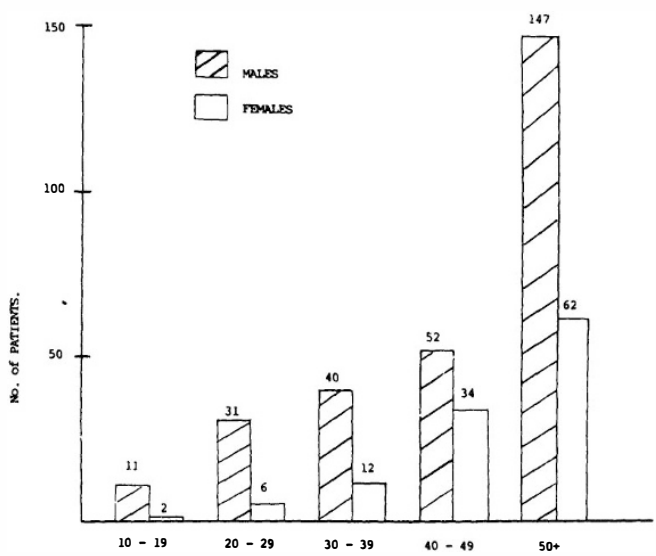

Fig. 1. Distribution of 397 patients with chronic glaucoma by age and sex.

AT microcomputer. The data was also analysed for patient response to treatment and follow-up.

\section{Results}

Of the 397 patients, $71 \%$ were male and $29 \%$ female. Twenty six per cent were aged less than 40 years at presentation (Fig. 1).

Complete data on age, sex, visual acuity and distance of residence from hospital was available on 379 patients. The visual acuity at presentation for different age groups is given in Figure 2 . Overall $34 \%$ of patients had a best visual acuity of less than $3 / 60$, and $52 \%$ of eyes were already blind (less than 3/60) at presentation. Fifty three per cent of men and $69 \%$ of women came from within 50 miles of the hospital, while $29 \%$ of men and $17 \%$ of women came from over 100 miles.

The numbers of patients by age group, sex, distance of residence from hospital and blindness are shown in Table I. Multivariate loglinear modelling was applied to the data. There was a significant association between being blind at presentation and age. The association was opposite to what one might expect, ie the younger the patient the greater the risk of blindness $(\mathrm{P}<0.001)$. (Table II)

Both distance of residence from hospital and sex of the patient influence the risk of blindness, and interact with each other. Females are more likely to be blind at presentation than males. The further the place of residence from hospital the greater the risk of blindness. Being female and living more than 50 miles from the hospital further increases the risk of blindness $(\mathrm{P}=0.015)$. (Fig. 3$)$

For those patients living more than five miles from the hospital $57 \%$ referred to the hospital had $6 / 18$ vision or better compared
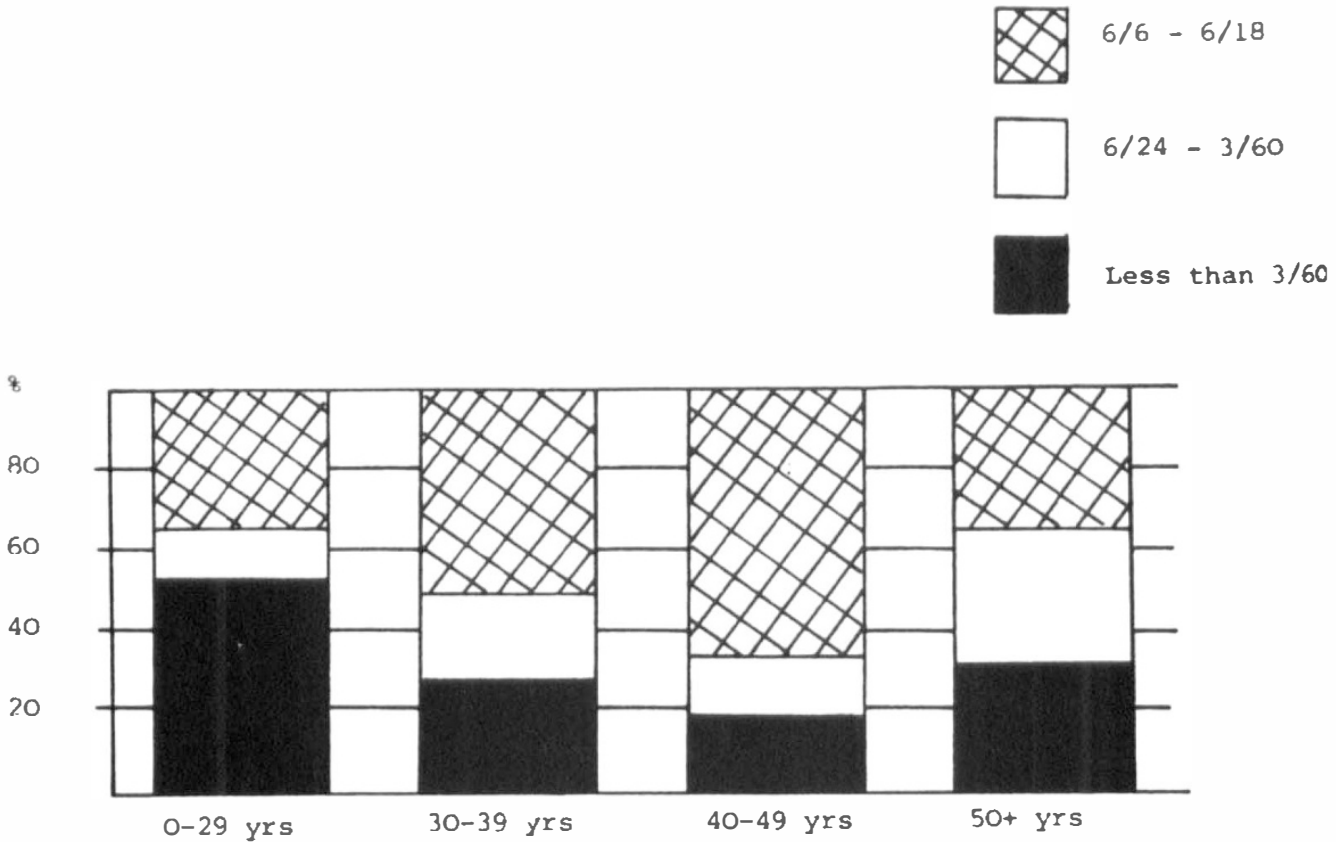

Fig. 2. Visual acuity in the best eye at presentation in 397 patients with chronic glaucoma. 
Table I 219 patients by age and sex according to visual status who lived within 50 miles of Bawku hospital

\begin{tabular}{|c|c|c|c|c|c|c|c|c|}
\hline \multirow[b]{2}{*}{ Age } & \multicolumn{4}{|c|}{ Males } & \multicolumn{4}{|c|}{ Females } \\
\hline & Not blind: & Blind: & & Total & Not blind: & Blind & & Total \\
\hline $10-19$ & 3 & 1 & $=$ & 4 & 1 & 0 & $=$ & 1 \\
\hline $20-29$ & 8 . & 8 & $=$ & 16 & 3 & 2 & $=$ & 5 \\
\hline $30-39$ & 17 & 5 & $=$ & 22 & 7 & 2 & $=$ & 9 \\
\hline $40-49$ & 24 & 4 & $=$ & 28 & 18 & 3 & $=$ & 21 \\
\hline \multirow[t]{2}{*}{$50+$} & 50 & 22 & $=$ & 72 & 28 & 13 & $=$ & 41 \\
\hline & 102 & 40 & $=$ & 142 & 57 & 20 & $=$ & 77 \\
\hline
\end{tabular}

160 patients by age and sex according to visual status who lived more 50 miles from Bawku hospital

\begin{tabular}{|c|c|c|c|c|c|c|c|c|}
\hline \multirow[b]{2}{*}{ Age } & \multicolumn{4}{|c|}{ Males } & \multicolumn{4}{|c|}{ Females } \\
\hline & Not blind: & Blind: & & Total & Not blind: & Blind & & Total \\
\hline $10-19$ & 3 & 3 & $=$ & 6 & 0 & 1 & $=$ & 1 \\
\hline $20-29$ & 4 & 11 & $=$ & 15 & 0 & 1 & $=$ & 1 \\
\hline $30-39$ & 10 & 4 & $=$ & 14 & 0 & 2 & $=$ & 2 \\
\hline $40-49$ & 14 & 6 & $=$ & 20 & 10 & 3 & $=$ & 13 \\
\hline \multirow[t]{2}{*}{$50+$} & 46 & 24 & $=$ & 70 & 5 & 13 & $=$ & 18 \\
\hline & 77 & 48 & $=$ & 125 & 15 & 20 & $=$ & 35 \\
\hline
\end{tabular}

with $38 \%$ who were self-referrals. The intraocular pressure was greater than $40 \mathrm{mmHg}$ in $72 \%$ of eyes of patients aged under 30 years, $61 \%$ of those aged $30-49$ years and $64 \%$ of those aged 50 years or more.

Medical treatment (pilocarpine drops, timolol drops or acetazolamide tablets alone or in combination) were given to 137 patients, and surgical treatment (trabeculectomy) was carried out in 188 patients. The decision for medical or surgical treatment was made on the preference of the patient and availability of surgery at the time of diagnosis. Only $30 \%$ of patients given medical treatment returned after two months for follow-up and by six months the number had fallen to $22 \%$. Twenty two per cent of patients seen at two months, and $17 \%$ seen at six months had an intraocular pressure of less than $22 \mathrm{mmHg}$ in at least one treated eye. Only $4 \%$ of patients treated medically were attending follow-up

Table II Multivariate log-linear modelling applied to risk factors associated with blindness

\begin{tabular}{lccr}
\hline Risk factor & Ratio statistic & DF & P value \\
\hline Age & 22.67 & 4 & $<0.001$ \\
Distance and Sex & 5.19 & 1 & 0.015 \\
\hline
\end{tabular}

and had an IOP less than $22 \mathrm{mmHg}$ at six months.

Of the 188 patients treated by trabeculectomy $39 \%$ were seen at two months and $17 \%$ at six months. Eight six per cent of patients seen at two months, and $84 \%$ at six months

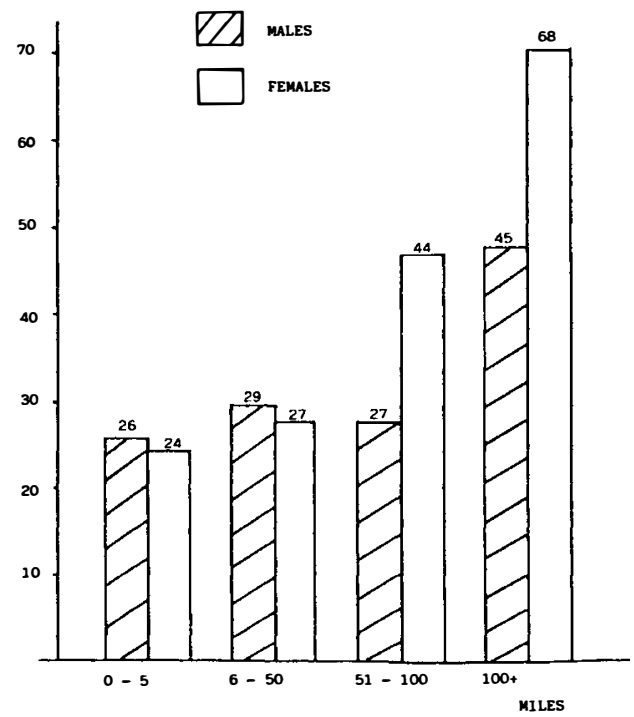

Fig. 3. \% of patients blind in both eyes from chronic glaucoma by distance of residence from Bawku Hospital for males and females ( $n=379$ patients). 
had an intraocular pressure of less than 22 $\mathrm{mmHg}$ in at least one treated eye (Fig. 4). Overall, only $19 \%$ of patients diagnosed as having glaucoma and given medical or surgical treatment were still attending for review at six months.

\section{Discussion}

Chronic glaucoma is a common cause of blindness in many parts of West Africa. The type of chronic glaucoma, either open angle or chronic angle closure could not be determined in this retrospective study, nor is it possible to know whether other ocular disease, particularly onchocerciasis may have contributed to the aetiology of glaucoma in some of the patients.

With these limitations in mind, it is useful to note some features of patients presenting with glaucoma, and the risk factors for blindness from glaucoma.

\section{(a) Sex}

There were more male patients than female (7:3). This may reflect a true difference, but is probably also because travelling is easier for men, who may also be more aware of available health care. Female patients were more likely to live nearer the hospital and were usually older at presentation than men. Onchocerciasis is more common in males which may be a contributory factor to the high male to female ratio. ${ }^{4}$

(b) Age

Twenty six per cent of patients were aged under 40 years at presentation. This early age of onset contrasts with chronic glaucoma in Caucasians. This is supported by evidence that black Americans have an earlier age of onset of glaucoma. ${ }^{5}$

Younger patients were more likely to present blind than older patients. It is possible that the earlier onset of disease is associated with a more aggressive and rapid rise in intraocular pressure. Chronic glaucoma in younger people may have a diffrent aetiology from that in the older population ${ }^{4}$ and needs further investigation.

\section{(c) Distance from Eye Care}

Nearly half the men and a third of the women

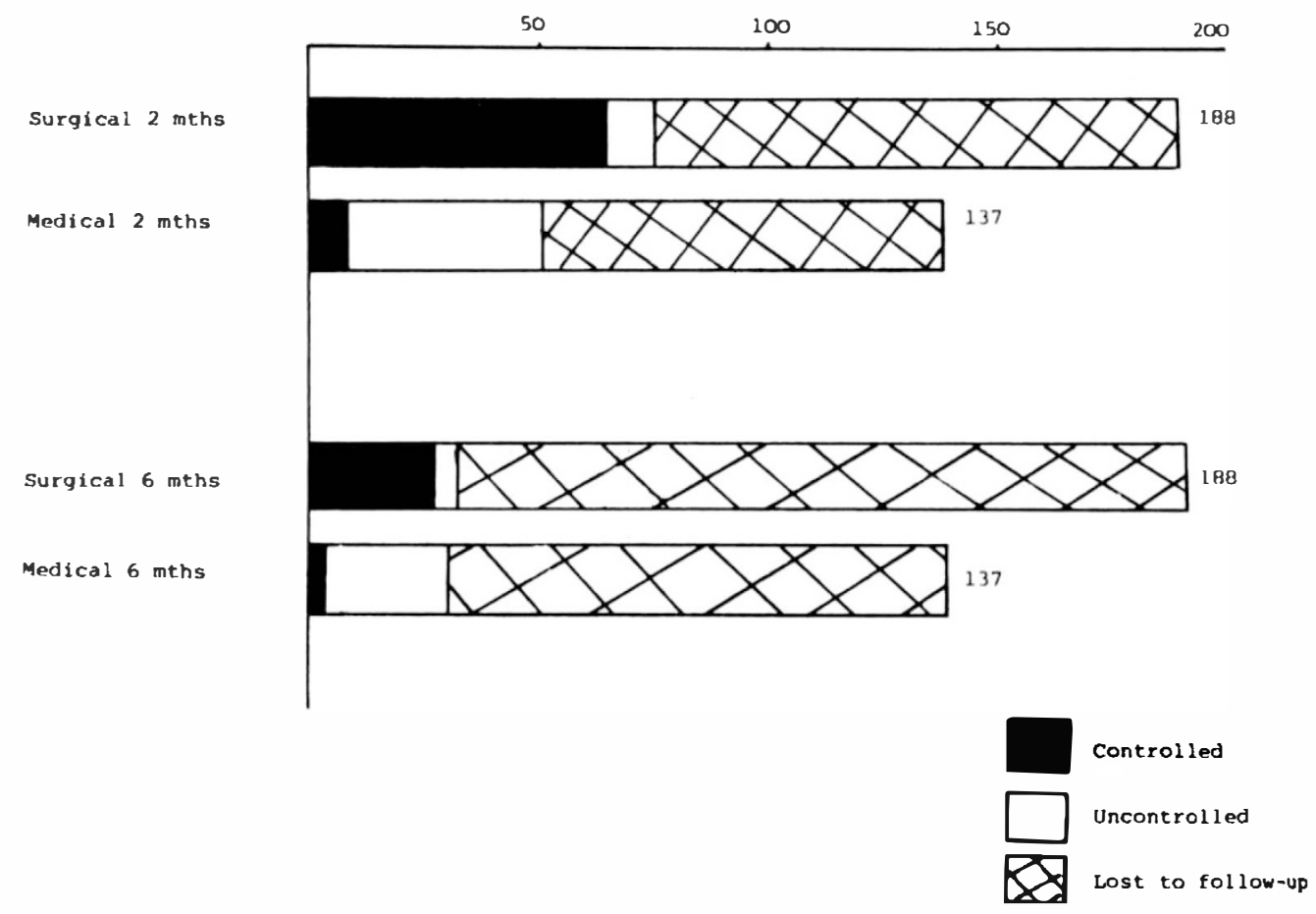

Fig. 4. Response to medical and surgical treatment. 
travelled more than 50 miles to obtain eye care. Patients living more than 50 miles from the hospital were four times more likely to present blind than patients living within 50 miles of the hospital (Fig. 3). Patients who were referred to Bawku having been examined in their villages by the mobile eye team had more preservation of vision than people who were self referred.

\section{(d) Treatment Possibilities}

The treatments presently available for chronic glaucoma are medical therapy, laser trabeculoplasty or filtration surgery. Laser trabeculoplasty may have limited long-term efficiency, ${ }^{6}$ and the technology is not available in most areas of Africa.

Medical treatment is unsatisfactory for the majority of patients because of lack of available medicines, expense, and poor compliance, as shown by the fact that only five patients out of an initial 137 treated medically had controlled intraocular pressure at six months follow-up.

Filtration surgery has been reported to give $\operatorname{good}^{7-9}$ and poor ${ }^{10,11}$ results in African eyes. Long term follow-up studies are required to see what the five and ten year success rate of surgery will be in the African patient. In this series we were only able to follow-up $39 \%$ of trabeculectomy patients at two months and $17 \%$ at six months, but of those followed up, $86 \%$ at two months, and $84 \%$ at six months had an intraocular pressure below $22 \mathrm{mmHg}$ without medical therapy. For the time being, there is little alternative to filtration surgery for the majority of patients with chronic glaucoma in Africa, who still have vision worth preserving.

\section{Prevention of Blindness from Chronic Glaucoma in Africans}

The majority of patients in West Africa with glaucoma present for treatment late. A major factor is the long distances patients often have to travel in order to receive treatment. This is also reflected by the extremely poor rate of follow-up after treatment $(19 \%$ at six months). It is therefore essential to have a simple means of identifying patients at high risk of having glaucoma available in health care facilities close to where patients live.
The possible criteria for referral which may be used by appropriately trained health workers depending on the availability of diagnostic equipment are:

(i) A vertical cup:disc ratio of 0.6 or more on ophthalmoscopy.

(ii) An intraocular pressure greater than 28 $\mathrm{mmHg}$ (Schiotz or Glaucotest)

(iii) Unexplained loss of vision $(55 \%$ of patients had vision in their better eye of less than 6/18)

Using these criteria it is likely that patients will be referred earlier to a specialist, while there is still the possibility of preserving a useful amount of vision in at least one eye. It is inevitable that a number of people will also be referred who do not hàve glaucoma.

At the present time filtration surgery offers the best hope for control of intraocular pressure and preservation of useful vision in the majority of African patients with chronic glaucoma.

\section{Conclusion}

Chronic glaucoma is a major cause of blindness in West Africa occurring in young as well as older people. Screening for glaucoma should therefore include people under the age of 40 years.

Early referral of patients with either, unexplained loss of vision, intraocular pressure over $28 \mathrm{mmHg}$, or vertical cup:disc ratio 0.6 or greater, could help diagnose patients at a stage when useful vision may still be preserved.

Filtration surgery is preferable to present medical therapy for the majority of patients from rural areas of West Africa, where the availability of medicines and follow-up services are limited.

\section{References}

${ }^{1}$ Olurin O: Primary glaucoma in Nigeria. East $A f r$ Med J 1972, 49: 725-34.

${ }^{2}$ Luntz M: Primary open-angle glaucoma. $S$ Afr Arch Ophthalmol 1973, 1: 131-40.

${ }^{3}$ Leske MC and Rosenthal J: Epidemiologic aspects of open angle glaucoma. Am J Epidemiol 1979, 109: $250-72$.

${ }^{4}$ Wormald R and Foster A: Clinical and pathological features of chronic glaucoma in North-East Ghana. Eye (in press). 
${ }^{5}$ Packer H, Deutsch AR, Lewis PM, et al.: Study of the frequency and distribution of glaucoma. J Am Med Ass 1959, 171: 1090-1.

${ }^{6}$ Fink IA, et al.: Therapeutic limitations of argon laser trabeculoplasty $\mathrm{Br} J$ Ophthalmol 1988, 72: 263-9.

${ }^{7}$ Wade A and Banta M: Long-term intraocular pressure results of trabeculectomy in black Africans with open angle glaucoma. J Fr Ophtalmol 1987, 10: $575-7$.
${ }^{8}$ Thommy CP and Bhar IS: Trabeculectomy in Nigerian patients with open angle glaucoma. $\mathrm{Br} J \mathrm{Oph}$ thalmol 1979, 63: 636-42.

${ }^{9}$ Sandford-Smith JH: The surgical treatment of open angle glaucoma in Nigerians. $\mathrm{Br} \mathrm{J}$ Ophthalmol 1978, 62: 283-6.

${ }^{10}$ Welsh N: Failure of filtration operations in the African. Br J Ophthalmol 1970, 54: 594-8.

${ }^{11}$ Berson $\mathrm{D}$, et al.: Filtering operations in Africans. Am J Ophthalmol 1969, 67: 395. 